\title{
KUIDAS PÄÄSEDA LÖÖGILE RAHVUSVAHELISTES AJAKIRJADES?
}

\author{
Kersti Lust
}

Ingliskeelse artikli avaldamiseks on kaks põhilist teed: kirjutada temaatilistes kogumikes või pürgida läbi tiheneva konkurentsisõela rahvusvaheliste ajakirjade veergudele. ${ }^{1}$ Kui 20. sajandi algul oli inglise, saksa ja prantsuse keelel teaduses võrreldav positsioon, siis sada aastat hiljem on inglise keel omandanud keelte hierarhias ülikeskse (hypercentral) koha. Selles keeles avaldatakse enamik rahvusvaheliste ajakirjade artiklitest ka humanitaarteadustes. ${ }^{2}$ Praegu on veel vara öelda, kas inglise keel tõrjub muud keeled täiesti kõrvale, nii et tekib ükskeelne rahvusvaheline teadus, või pingutab rahvusvaheline teadlaskond mitmekeelse teaduse säilimise nimel.

Iroonilises võtmes on rahvusvahelise publitseerimisvõidujooksu telgitaguseid kirjeldanud psühholoogiaprofessor Jüri Allik, kes kostitab 2014. aastal ajakirjas Akadeemia avaldatud artiklis lugejaid arvukate karikatuursete näidetega nii oma kogemustest kui ka üleilmsetest skandaalidest. ${ }^{3}$ Allik ootab, et toimetajate ja "eeltsensuuri" (eelretsenseerimise) seatud kunstlikud ja mõttetud tõkked publitseerimiselt langeksid ning jääks vaid järelretsenseerimine, kuid selle ajani tuleb teadusilmas tegutsejail siiski kohaneda kehtivate mängureeglitega. Alliku käre kirjatükk ärgitas nii mõndagi sotsiaal- ja humanitaarteadlast publitseerimise köögipoolt paljastama, kuid ajaloolased on sel teemal pigem vaikinud. ${ }^{4}$ Järgnevaid täiesti

\footnotetext{
1 Silmas peetakse ajakirju, mis ei keskendu Baltikumile nagu Journal of Baltic Studies. Eeskätt on tegemist angloameerika väljaannetega, mille toimetus ei pruugi alati asuda Suurbritannias, Ameerika Ühendriikides või Kanadas, kuid mis ilmuvad mõne rahvusvahelise konsortsiumi (Taylor \& Francis, Elsevier jt) või angloameerika ülikooli (Oxford, Cambridge jt) kirjastamisel.

2 Rainer Enrique Hamel, "The dominance of English in the international scientific periodical literature and the future of language use in science", AILA Review 20 (2007), 53-71. Inglise keele tähtsuse ja teiskeelsetel inglise keeles avaldamisel tekkivate raskuste kohta vt Mary Jane Curry and Theresa M. Lillis, Academic writing in a global context: The politics and practices of publishing in English (New York: Routledge, 2010); Ramón Plo Alastrué and Carmen Pérez-Llantada, English as a scientific and research language (Berlin: de Gruyter, 2015).

3 Jüri Allik, "Publitseerimise huvitav maailm", Akadeemia 9 (2014), 1550-1575.

4 Vaimukas võtmes on lähenenud nt Mati Rahu, Talis Bachmann, "Teadusartikkel: eelretsenseerimisprotsess", Akadeemia 1 (2017), 38-71; Leo Luks, "Ta ilmub siiski! Ühe käsikirja odüsseia", Sirp, 08.01.2016.
} 
kiretuid tähelepanekuid kirja pannes tuginesin nii oma kogemustele kui ka vestlustele kolleegidega ja Tallinna Ülikooli suvekooli kursusel "How to get published?" räägitule. ${ }^{5} \mathrm{Nii}$ ei tule juttu ainult sellest, kuidas tulemuslikult üllitada artikleid 18.-20. sajandi eesti talurahva ajaloost, vaid püüan üldistada eri valdkondades tegutsejate arvamusi, eesmärgiga julgustada kätt proovima nii neid, kes siiani on oma töö suunanud eesti lugejale, kui ka neid, kelle senised katsed pole soovitud tulemuseni viinud.

\section{Avaldamiskoha valik}

Artiklit kirjutades on hea hoida silme ees üht kindlat ajakirja. Valikut tehes tasuks arvestada mitut asjaolu: kus on ilmunud kavandatavas artiklis viidatavad tööd (võimalusel pakkuda samale väljaandele); millise auditooriumini soovitakse jõuda (kas üleilmse või regionaalse; kas geograafiliselt, ajaliselt või temaatiliselt piiritletud huvidega teadlaskonnani); kui sageli ajakiri ilmub; kui kaua vältab eelretsenseerimine ja kui pikk on lõtk käsikirja vastuvõtmisest selle ilmumiseni; kes on väljaande toimetaja(d); milline on ajakirja viidatavus (nt h5-indeks), koht pingereas ning kaastööde vastuvõtuprotsent. ${ }^{6}$ Väljaanded erinevad nii regionaalsetelt eelistustelt kui ka ootustelt temaatikale ja formaadile. Ajakirja temaatiline fookus ja metodoloogilised eelistused - kas kvantitatiivne või kvalitatiivne, empiiriline või teoreetiline - ja eesmärgid selguvad, kui tutvuda väljaande kodulehe ning viimaste aastakäikudega.

Eesti ja Baltimaade ajalugu ei tarvitse väljast vaadates paista oluline ega põnev. Kahel korral on üks ja sama ajakiri mulle kohese äraütlemise põhjuseks toonud huvipuuduse Baltikumi vastu. Paari ajakirja toimetus on palunud artikli juures olevat Eesti kaarti täiendada Läänemere maade

\footnotetext{
Tallinna Ülikooli suvekooli kursus "How to get published and how to supervise?" (22.-25.07.2019), kus lisaks Texase Austini Ülikooli professor Diana DiNittole jagasid oma kogemusi TLÜ professorid Peeter Selg ja Karmen Toros. Kodu- ja välismaised ajaloolased, kellega vestlesin ja kirju vahetasin, jäävad anonüümseks. Ingliskeelseid soovitusi leiab internetiavarustes mitmelt poolt, nt https://uk.sagepub.com/en-gb/eur/ how-to-get-published\#Guide (viimati vaadatud 14.08.2020); https://researcheracademy. elsevier.com/writing-research/fundamentals-manuscript-preparation (viimati vaadatud 14.08.2020).

Ajakirjade mõjukuse ehk viidatavuse kohta leiab infot nt andmebaasist Scimago Journal \& Country Rank (https://www.scimagojr.com/), mis arvestab ka seda, millistes väljaannetes ajakirjadele viidatakse. Ajakirjade viidatavust viimase viie aasta jooksul (h5-index) arvutab Google. Otsida tuleb valdkondade ja alamvaldkondade kaupa (Categories $>$ Subcategories $>$ History). https://scholar.google.com/citations?view_op=top_ venues\&hl=en\&vq=hum_history.
} 
kaardiga, sest osa lugejaid ei tea, kus Eesti asub. ${ }^{7}$ Eesti ja Baltikumi perifeersus või eksootilisus ei ole siiski nii suur takistus kui temaatiline sobimatus. Kitsamale ringile suunatud uurimistulemusi ei tasu pakkuda ajakirjale, millel pole ajalisi või temaatilisi piiranguid või regionaalset fookust, sest tagasi lükatud võib saada ka kaastöö, mille sisu ja teostust peab toimetuskolleegiumi liikmest retsensent "muljetavaldavaks" ja "äärmiselt heaks". Küsimuses, mil määral sõltub artiklite tagasilükkamine vastavusest kvaliteedikriteeriumidele ja konkurentsisõela tihedusest ning mil määral valitud teema atraktiivsusest (nt aktuaalsusest), uurijate arvamused lahknevad. Kuna seni on Eesti ajaloolased rahvusvahelistes ajakirjades vähe avaldanud, ei saa öelda, kas kõrgeima prestiižiga väljaanded, nagu Past \& Present, The American Historical Review, The Journal of Economic History jt, jäävad Eesti ainesega tegelevatele uurijatele kättesaamatuks, kuna need kuuluvad teadusmaailma, kus Eesti ja Baltimaad on marginaalsed, või pole neis püütudki avaldada. ${ }^{9}$ 20. sajandi poliitilisest ajaloost kirjutades võivad ajakirja veerud jääda suletuks ka ideoloogilistel motiividel, kui seisukohad on vastukarva toimetajatele, retsensentidele ja/või mõjuvõimsale teadlaskogukonnale. Teenekate tegijate vastu ongi vähem lootust saada algajail.

Toimetus või toimetaja otsustavad, kas saata käsikiri retsenseerimisele, ja kui, siis kellele. Toimetajaid võib olla nii üks kui ka mitu ning viimasel juhul on otsus üldjuhul kollektiivne (käsikirjade pingerea koostamiseks võidakse kasutada hindeid - A, B jne). Toimetajast sõltub ka see, milliseid retsensentide märkusi tuleb käsikirja ümbertegemisel arvestada ja millised võib jätta tähelepanuta. Vastukäivate arvamuste puhul peab ta tegema valiku emma-kumma seisukoha kasuks. Üks negatiivne, isegi hävitav retsensioon ei pruugi saada saatuslikuks, kui toimetaja ei pea (pahatahtlikku) kriitikat pädevaks või põhjendatuks ning teine (ja kolmas) hindaja on soodsalt meelestatud ja soovitavad töö kindlasti avaldada. Retsensentide hinnangud ei ole toimetajale siduvad, ta võib võtta kaastöö suhtes negatiivse

\footnotetext{
Mõlemal juhul oli tegemist Cambridge'i Ülikooli kirjastuse all ilmuvate ajakirjadega.

8 Esimene retsensent arvas: "I was very impressed by this article" [...] "an extremely well-researched case study" [...] "the questions it sets itself are those of interest to a more limited historiography than our generalist readers would expect to come across in our pages", mistõttu see oleks "more appropriately located in a more specialist journal". Teine retsensent leidis, et artikkel ei sobi "for a general history journal. I have no doubt that the submission is based on a great deal of research, but I would suggest that the author should turn to more specialised anthropology or area studies journals for possible publication."

9 Silmas peetakse artikleid ja mitte arvustusi. 2020. a ilmusid esimesed Eesti autorite artiklid väga kõrgelt hinnatud ajakirjas History and Theory (Marek Tamme ja Juhan Hellerma sulest), kuid tegemist pole Eesti-aineliste uurimustega.
} 
hoiaku ka vaatamata kolmele positiivsele retsensioonile ning esitada oma nõudmisi. Seepärast tasuks ajakirja valikul vaadata ka seda, mis teemadel on toimetaja(d) publitseerinud. Sarnaste uurimishuvide korral võib loota kaastöö positiivsemat vastuvõttu; veelgi enam - kui tegemist on oma valdkonna tuntud ja teeneka teadlasega, võib ta retsensentide arvamustest vähem sõltuda ja vastukäivate hinnangute korral artikli siiski avaldada. Kuna paljudes kõrgetasemelistes väljaannetes on konkurents viimase kümne aasta jooksul järsult tihenenud ja üha suurem osa kaastöid lükatakse tagasi, on mõistlik arvestada kõiki asjaolusid, mis võiksid käsikirja vastuvõtmisele kaasa aidata.

\section{Formaat}

Ida-Euroopa ajaloolased avaldavad rahvusvahelistes ajakirjades märksa harvem kui nende läänepoolsed kolleegid. Miks? Pole harjumust või keeleoskust? Kasutatakse iganenud metoodikat? Pole uudseid mõtteid ega paeluvat materjali või ei osata neid sobivalt pakendada?

Esitus ehk spetsiifiline akadeemiline formaat on väga oluline. ${ }^{10}$ Lisaks üldistele vormireeglitele on igal valdkonnal (majandusajalugu, ideede ajalugu jne) omad eripärad. Akadeemiline kirjutamine on käsitööoskus, mis on õpitav. Artiklilt eeldatakse probleemikesksust, orienteerumist asjakohastes teooriates ja kontseptsioonides, selget struktuuri, süstemaatilist ja argumentatiivset esituslaadi. Hea artikkel algab probleemipüstituse ja varasemate vastakate seisukohtade tutvustamisega. Eesmärk on põhjaliku ja süstemaatilise analüüsiga veenda lugejaid oma seisukohtade vettpidavuses käsiteldavas aegruumis. Üldisemaid väiteid ja järeldusi pikitakse kõnekate näidetega. Historiograafiline ülevaade esitatakse eelistatult sünteetiliselt, mitte loetlev-kirjeldavas stiilis. Uurimisprobleemi ei pea sugugi dikteerima põletavad debatid ajalooteaduse eesliinil, kuid artikkel peab astuma dialoogi rahvusvahelise uurimisega, st suutma oma uurimisainese ja -probleemi suhestada teiste sarnaste või võrreldavate uurimistöödega, kas või aastakümnete tagusest ajast, ja rikastada üldist uurimisseisu mõne uudse aspekti või argumendiga. Ajaloos ei lähe teemad päevakorrast päris maha, vaid pigem vajuvad unustusehõlma. Unarusse jäänud temaatika taaselustamist võidakse suisa tervitada. Mitu kolleegi nõustus väitega, et rahvusvaheline potentsiaal on pea igal Eesti-ainelisel teemal (ja mitte ainult õõnsalt kõlavail, konjunktuursetel teemadel $)^{11}$, kui see oskuslikult siduda üleilmsete

10 Käibel on termin Anglo-American tradition või Anglo-American writing.

11 Tiina Kirss, "Eesti humaniora häirekellad", Sirp, 06.04.2007. 
või üleeuroopaliste protsesside, nähtuste või sündmustega ning üleilmsete uurimisprobleemidega. Mõne meelest tagab avaldamise eeskätt kindlakskujunenud formaadi järgimine, teise arvates aga on olulisemad autori uudne mõtlemine ja põnev aines. Üllatava või ebatavalise materjali ning sihtkeele oskuse tähtsuse suhtes langevad aga arvamused ühte. Tiina Kirss on seejuures rõhutanud, et inglise keeles kirjutamine ei tähenda eestikeelse artikli tõlkimist inglise keelde, vaid tekst tuleb teadlikult "välja" kirjutada, lülitudes ümber teistsugusele kommunikatiivsele taustale. ${ }^{12}$

Hea artikkel keskendub olulisimale ja väldib liigseid detaile, kõrvalepõikeid ning kõrvalteemade arendusi. Selge, asjatundlik, põhjalik ja loogiline tekst veenab lugejaid. Sissejuhatus peab sobituma kokkuvõttega ning väited järelduma tõenditest (hoidudes tõendamata väidetega žongleerimisest). Tabelite ja arvjooniste eesmärk on teksti mõistmist hõlbustada ja kiirendada. Kokkuvõttes esitatavad tulemused paigutatakse laiemasse konteksti ja suhestatakse varasemate uurimustega, nii et lugeja saab täpselt aru, milliseid varasemaid väiteid ja arusaamu autor soovib kinnitada ning milliseid kahtluse alla seada või kummutada. Kokkuvõttes visandatakse ka edasised uurimisülesanded ning osutatakse oma tulemuste võimalikele puudustele, nende kehtivuse piiridele, ehkki viimasega ei sobi artiklit lõpetada.

Kirjeldatud formaadi võib selgeks õppida nt artikleid lugedes ja neid üksipulgi analüüsides. Kirjutamisoskust arendab raamatute retsenseerimine. Head kirjutajad on karjääri algaastail sageli rohkelt arvustusi produtseerinud. Vahel soovitatakse hoida omale meelepäraseid, n-ö näidisartikleid töölaual käepärast, et neisse aeg-ajalt kiigata ja neist eeskuju võtta. Varasemast historiograafiast saab ettekujutuse ülevaateartiklitest (review articles) või näiteks ka doktoritööde historiograafiaosadest, sest need on sageli üsna põhjalikud. Nii saab kerge vaevaga teada tähtsamad autorid ja vaidlusalused küsimused. Valdav osa minu artiklitest on sündinud arhiiviallikatest saadud ideedest ja sobiva rahvusvahelise võrdlusmaterjali olen hiljem juurde otsinud.

Artikli võtmetähtsusega osad on sissejuhatus, allikad ja metoodika, kokkuvõtvad järeldused ja lühikokkuvõte. Nendele koondavad oma tähelepanu retsensendid ja enamasti ka lugejad, sest teemakohast kirjandust ilmub palju ja kõigeks ei jätku aega. Retsensendid loevad küll läbi kogu kirjatüki, kuid kõige vähem sallivad nad puudusi nimetatud osades. Sõltuvalt uurimisvaldkonnast on analüüsivõtete sobivus erineva kaaluga. Mõni analüüsivõte võib (retsensendi arvates) olla kujunenud standardiks ja

$12 \quad$ Ibid. 
selle eiramine ning asendamine teistsugusega võib lõppeda artikli ümbertegemisega, vähemasti juhul, kui autorid on vähetuntud riigist nagu Eesti ja retsensent oma valdkonna tipptegija. ${ }^{13}$ Ühe sellise juhtumi puhul kaks retsensenti ebatüüpilist lahendust puuduseks ei pidanud, kuid kolmas ei soostunud sellega mitte mingil juhul. Kui analüüs sai ümber tehtud, kiitis toimetus käsikirja hoobilt heaks, pööramata vähimatki tähelepanu asjaolule, et tulemused said märksa kesisemad. Sobiva meetodi teemal olen korra piike murdnud vastutava toimetajaga (ehkki kolm retsensenti teemat üldse ei tõstatanud) ning artikkel avaldati pärast äärmiselt põhjalike metoodiliste selgituste lisamist.

Lühikokkuvõtet on harjutud pidama väheoluliseks kohustuslikuks lisandiks, kuid paraku paljud lugejad sellega piirduvadki. Lühikokkuvõtte pikkus eri väljaannetes varieerub, jäädes enamasti 100-300 sõna vahele. See peaks sisaldama probleemipüstitust ja selle põhjendust, nimetada tuleks põhiallikad, meetodid ja üks-kaks peamist järeldust.

\section{Keel ja stiil}

Hea artikkel on ühtaegu lugejasõbralik ja autori nägu. Selline artikkel on selgelt kirjutatud ning - sõltuvalt viljeldavast valdkonnast - ka haaravalt jutustatud. Ameerika Ajalooühingu (American Historical Association) kunagine president William Cronon on märkinud, et kirjutada tuleb nii, et see ei peletaks lugejaid eemale, vaid tõmbaks neid ligi. ${ }^{14}$ Teisisõnu - tekstist ei tohi elu välja imeda. Tekst on lugejasõbralik, kui erialast žargooni pruugitakse nii vähe kui võimalik ja nii palju kui vajalik. Laiema lugejaskonnani jõudmiseks tasub spetsiifilisi termineid tarvitades iga kord mõelda, kas see on arusaadav ka erialavälisele inimesele, ning vajadusel seletada mõiste lahti, anda taustteavet või lisada mõni konteksti avav sõna või väljend. Heast tekstist ei puudu ka huumor. Autori "hääl”, tema positsioon peab selgelt väljenduma.

Ajaloos, ja humanitaarteadustes laiemalt, on lisaks teadusliku mõtte teravusele alati hinnatud oskuslikku sõnaseadmist. Kohmaka keelekasutusega

\footnotetext{
13 Retsensendid on küll anonüümsed, kuid ikka juhtub, et nad konverentsil või muul teadusüritusel artikli autorile või tema kolleegile juurde astuvad ja oma retsenseerimisest teada annavad. Nimetatud juhtumil oli tegemist kõnealuse analüüsivõtte silmapaistvaima rakendajaga majandusdemograafias. Ka retsenseerimine on anonüümne ja autori(te) päritolu retsensendile teadmata, kuid eestimaine uurimisobjekt, eestikeelsete allikate kasutamine ja varasemad uurimistööd reedavad käsikirja autori kergesti.

14 Viidatud Rachel Toor, "Becoming a 'stylish' writer", Chronicle of Higher Education, 02.07.2012.
} 
neil aladel kaugele ei jõua. Jagan seisukohta, et heas, nõtkes inglise keeles suudab kirjutada vaid see, kes selles keeles ka mõtleb. Marju Lepajõe on asetanud lati veel kõrgemale ja kuulutab, et originaalse kirjatüki saab kirjutada vaid emakeeles ning võõrkeelde tuleb see lasta tõlkida "meistril". ${ }^{15}$ Keelelise toimetamise vajadusele osutamine on muutumas toimetajate ja retsensentide n-ö valvemärkuseks. Sellise soovituse on pidanud alla neelama isegi inglane, kes kolleegi käsikirja oma parimate oskuste kohaselt ära tõlkis. Kui autor ei pärine inglise keeleruumist, on märkus keele kohta tavapärane isegi siis, kui teksti on redigeerinud professionaalsed keeletoimetajad (seda on kurtnud ka Helsingi ja Turu Ülikooli ajaloolased). Leidub ajakirju, kus vastutav toimetaja loeb käsikirja korduvalt hoolega läbi, parandades kõik selles leiduvad ebakohad; samal ajal on arvukalt teisi, kus toimetaja ei tee teksti ühtki muudatust. Osades ajakirjades redigeerimise faasis keelt (enam) ei toimetata ja korrektne keel on vaid autori enda vastutus. ${ }^{16}$ Seepärast on mõistlik lasta tekst üle vaadata võimalikult püüdlikul ja kogemustega keeletoimetajal, vältimaks artikli vääritimõistmist või arusaamatuks jäämist.

\section{Eelretsenseerimine}

Retsensentide valiku aluseid on tutvustanud Jüri Allik ning eriti põhjalikult Talis Bachmann ja Mati Rahu. Bachmann ja Rahu kirjeldavad ilmse naudinguga, kuidas retsensente leitakse ja milline on nende tüpoloogia, ning annavad nõu, kuidas etteheidetele "õigesti" vastata. ${ }^{17}$ Allik mainib muu hulgas, et loogiline on saata käsikiri retsenseerimiseks neile, kellega selles käsikirjas polemiseeritakse või kes seda teemat on edasi arendanud..$^{18}$ Mõne minu töö kohta on tõepoolest küsitud arvamust teadlastelt, kellega olen väidelnud, ja kahel juhul on retsensent lühidalt deklareerinud, et ta käsikirjas esitatud seisukohtadega ei nõustu, kuid nende üllitamist ei takista. Kolmandal juhul aga ei pidanud toimetaja mahukast, umbes 300o-sõnalisest arvamusest (s.o pikkuse poolest kolmandiku artikli mõõtu tekstist) arvestamisväärseks ühtki kriitilist kommentaari. Seepärast oletan, et ajalooajakirjade toimetajad ei eelista arvustajatena neid, kellega polemiseeritakse; pigem on see sundvalik asjatundjate nappuse korral.

15 Marju Lepajõe, "Milleks rahvuslikkusele tõlkimine?”, Akadeemia 9 (2014), 1542-1543.

16 Minu kogemust mööda nt Sage'i ja Taylor \& Francise gruppi kuuluvad ajakirjad Journal of Family History, The History of the Family ja Scandinavian Economic History Review.

17 Allik, "Publitseerimise”, 1554-1568; Rahu, Bachmann, “Teadusartikkel”, 38-71.

18 Allik, "Publitseerimise", 1554. 
Toimetaja soovitused ja retsensentide märkused tuleb hoolikalt läbi lugeda. Allik on toonud mõjuva näite ühest retsenseerimiskogemusest, kus ainus jälg tema tööst oli artikli lóppu lisatud mõttetu märge, et autor tänab retsensente. ${ }^{19}$ Üldiselt suhtuvad toimetajad arvamustesse tõsiselt ja märkustele vastates tuleb näidata, soovitavalt punkthaaval, mida on käsikirjas muudetud (võimalusel viidates leheküljenumbritele), ja kui kõiki etteheiteid või soovitusi pole võimalik või otstarbekas arvestada, tuleb seda põhjendada. Taktikaliselt õigesti vastamine toob edu, samal ajal kui retsensendiga vaidlemine annab harva soovitud tulemuse. ${ }^{20}$ Üks kolleeg soovitas ülekohtusena näivat kriitikat viisakalt ignoreerida, seda näiteks mõne üldsõnalise lausega pareerides. Isegi kui retsensentide märkused tunduvad asjatundmatud, alavääristavad või põlastavad, tuleb vastustes jääda konstruktiivseks, viisakaks ja lugupidavaks. Neid vastuseid ei tarvitse lugeda ainult ajakirja toimetaja, vaid ta võib need edastada samadele retsensentidele küsimusega, kas nad kiidavad käsikirja uue variandi heaks ning rahulduvad autori selgitustega. Veelgi enam - vastust ei pruugi näha ainult konkreetse arvamuse kirjutaja, vaid kõik hindajad. Eestis, kus "kõik tunnevad kõiki", retsenseerimisel väga süvitsi või teravaks pigem ei minda (muidugi leidub ka tõeliselt põhjalikke retsensente). Ka toimetajad üldjuhul ei oota pikka soovituste loetelu ega sea avaldamise tingimuseks nende täitmist.

\section{Kokkuvõtteks}

Rahvusvahelistesse väljaannetesse kirjutamine ja kapriissetele retsensentidele meele järele olemine osutub sageli tülikaks ja aeganõudvaks, kuid seal avaldamine toob uusi kontakte ja loob eelduse osalemiseks rahvusvahelises teadusdiskussioonis. Vaev võib end kuhjaga ära tasuda, kui kandideerida uurimisstipendiumile, teadusrahastusele või akadeemilisele ametikohale. Taotluste hindajail on mugav ajakirja maine järgi otsustada avaldatu kvaliteedi üle. Hea artikkel on dialoogis rahvusvahelise teadusega ning ajakirjadest on sobivaimad sellised, kus arutletakse samadel teemadel või on seda varemalt tehtud. Sarnase temaatilise fookusega mainekaid ajakirju on enamasti mitu ja ühes kohas maha laidetud käsikiri võib saada teise toimetaja ja uute retsensentide poolt parema hinnangu. Mitmed uuringud on näidanud, et kahe või kolme retsensendi arvamused langevad harva

\footnotetext{
$19 \quad$ Ibid., 1552.

20 Rahu, Bachmann, “Teadusartikkel”, 55-59.
} 
omavahel kokku. ${ }^{21}$ On hea, kui käsikirja loeb üle ka kolleeg, sest kõrvalpilgust on alati kasu.

\section{Авstract: How to get published in international journals?}

The number of Estonian historians who publish regularly in international journals is fairly small. The aim of this article is to encourage historians to take this step and to give tips on how to succeed in the increasingly competitive world of international publishing. The tips are based on the lectures presented at the summer school "How to get published?" (organised by Tallinn University in 2019) alongside the author's experiences and conversations with other colleagues. The topics considered include how to select a journal, compose an article and its key parts, impress editors and please peer-reviewers. Special attention is paid to the importance of language and style. Having a native speaker read the draft is essential.

The article provides both general guidelines as well as specific suggestions for how to publish on Estonian history. The paper describes the main characteristics of what has been called the "Anglo-American model of academic writing". The colleagues interviewed for the article agreed that, in principle, it would be possible to publish on most topics of Estonian history and there is no need to pick a globally attractive and currently trending topic. For that, the research question has to be linked to global or European developments, events or phenomena and to discussions in the respective field of research. The colleagues, however, disagreed on the issue of whether it is more important to follow the conventional style and format of the journal or to present novel ideas. There was a consensus that surprising source material, intriguing results, and high-quality English certainly increase the article's chances of getting published.

KeYwORDs: academic writing; publishing; history

Kersti Lust is Senior Research Fellow at Tallinn University.

\footnotetext{
${ }_{21}$ Allik, "Publitseerimise", 1565. Usutavasti peab J. Allik silmas loodus- ja täppisteadusi, kuid oletan, et humanitaarvaldkonnas pole subjektiivsus vähem tõsine probleem. * Correspondence: School of Governance, Law and Society, Tallinn University, Narva rd 25, 10120 Tallinn, Estonia. E-mail: kersti.lust@tlu.ee
} 
